\title{
Issues concerning the on-going care of patients with comorbidities in acute care and post-discharge in Australia: a literature review
}

\author{
Allison Williams BAppSc(Nsg) MNS RN \\ Lecturer, School of Postgraduate Nursing, University of Melbourne, Victoria, Australia
}

and Mari Botti BA RN

Associate Professor of Nursing, Deakin University, Burwood, Victoria, Australia

Submitted for publication 23 October 2001

Accepted for publication 10 July 2002

Correspondence:

Allison Williams,

Renal Stream Co-ordinator, School of Postgraduate Nursing,

The University of Melbourne,

Level 1, 723 swanston Street,

Carlton Victoria 3053,

Australia.

E-mail:afw@unimelb.edu.au

Williams A. \& BОтTі M. (2002) Journal of Advanced Nursing 40(2), 1-10 Issues concerning the on-going care of patients with comorbidities in acute care and post-discharge in Australia: a literature review

Background. Advances in medical science and improved lifestyles have reduced mortality rates in Australia and most western countries. This has resulted in an ageing population with a concomitant growth in the number of people who are living with chronic illnesses. Indeed a significant number of younger people experience more than one chronic illness. Large numbers of these may require repeated admissions to hospital for acute or episodic care that is superimposed upon the needs of their chronic conditions.

Aim. To explore the issues that circumscribe the complexities of caring for people with concurrent chronic illnesses, or comorbidities, in the acute care setting and postdischarge.

Methods. A literature review to examine the issues that impact upon the provision of comprehensive care to patients with comorbidities in the acute care setting and postdischarge.

Findings. Few studies have investigated this subject. From an Australian perspective, it is evident that the structure of the current health care environment has made it difficult to meet the needs of patients with comorbidities in the acute care setting and postdischarge.

This is of major concern for nurses attempting to provide comprehensive care to an increasingly prevalent group of chronically ill people.

Conclusion. Further research is necessary to explore how episodic care is integrated into the on-going management of patients with comorbidities and how nurse clinicians can better use an episode of acute illness as an opportunity to review their overall management.

Keywords: acute, chronic illness, comorbidities, care, continuity, co-ordinated, episodic, economics, health services

\section{Introduction}

A consequence of the reduction in mortality rates in western countries such as Australia, United States of America (USA) and Canada is a 'greying' population and a growth in the number of people who are living with chronic illnesses (Davis \& George 1998, Badley et al. 1999, Ogle et al. 2000, Lubkin \& Larsen 2002). Indeed, most of the elderly and a significant number of younger people will experience more than one chronic illness in their lifetimes (Davis \& George 1998,

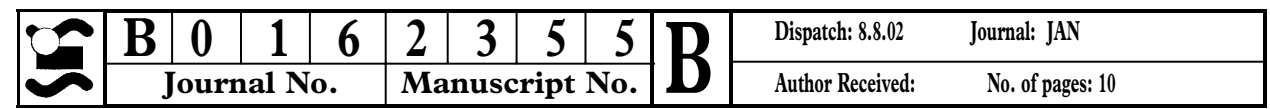


Badley et al. 1999, Lorig et al. 1999, Lubkin \& Larsen 2002). Chronic illness is defined as

A permanently altered health state, caused by a nonreversible pathological condition, that leaves residual disability that cannot be corrected by a simple surgical procedure or cured by a short course of medical therapy (Miller 1992, p. 4).

Chronic illnesses are considered synonymous with deterioration, reduced competence, increased needs, physical and emotional pain, and increased dependence (Gignac \& Cott 1998). The outcomes of experiencing chronic illnesses may necessitate visits to doctors and other health practitioners, therapies, surgery, dependency on equipment and people, sadness and fear, hospital stays, residence in a nursing home and early death (Verbrugge \& Patrick 1995). Unfortunately, having one chronic condition offers little or no protection against developing another; indeed, it is often associated with the subsequent development of further conditions (Seeman et al. 1989), particularly if the secondary condition is a complication of the primary diagnosis. Large numbers of people with a variety of concurrent chronic illnesses, such as arthritis, bowel conditions and diabetes, have the potential to require repeated admissions to hospital for episodic care that is superimposed upon their chronic illnesses. This mixture of acute and chronic needs presents an added complexity to the dimensions of care required (Grau \& Kovner 1986).

Nurses play a pivotal role in the care of people who are chronically ill (Temmink et al. 2000), both in the context of acute care and in the community. However, few studies have examined comorbidity beyond its effect on length of stay, specific treatment, and the burden of care for the patient's family (Grau \& Kovner 1986, Lindsey et al. 1994, Sarna \& McCorkle 1996, Schaldach 1997). The literature pertaining to issues surrounding the nursing care of people with individual chronic illnesses is extensive (LeMone \& Burke 2000, Smeltzer \& Bare 2000), and these issues continue to attract research attention. Evidence based practice (Dawes et al. 1999, Hamer \& Collinson 1999) has generated studies on a plethora of 'best practice' nursing skills, such as wound 2 management common to many chronic illnesses (Selim et al. 2001). However, the specific issues that relate to caring for comorbidities have received scant discussion in the nursing literature to date. Further, little attention has been given to the complexity of managing potentially conflicting and multiple illnesses in the setting of acute care.

Comorbidities alter the course or outcome of diseases (Feinstein 1970, Kaplan \& Feinstein 1974, Verbrugge et al. 1989). When a person with a combination of chronic illnesses is admitted to an acute care setting, the associated complexity and need for continuity and co-ordination of care become paramount considerations. Although health care institutions claim that their central interest is the patient, there is conflict between existing paradigms governing care.

\section{The study}

\section{Method}

The purpose of this paper is to discuss the current market led health care environment in Australia that makes it difficult to achieve the objective of co-ordinated and continuity of care for people with comorbidities in acute care and postdischarge. Literature responding to the keywords of chronic illness and comorbidity in the context of continuity and coordinated care were identified primarily using the Cumulative Index of Nursing and Allied Health Literature [CINAHL], 3Medline, Expanded Academic ASAP and AUST health databases over the past 20 years. As the search revealed a disappointing result, associated reference lists, books and media that were considered to inform the topic were included. The literature was then examined for common themes and concepts and reported using descriptive analysis. Specifically, issues concerning the tension between health care funding and care, the concern of nurses to preserve the caring relationship and provide comprehensive care, and difficulties arising from a dominant biomedical perspective of cure and research that was founded upon acute care interests are discussed.

\section{Findings}

\section{Health care funding environment}

Advances in medicine and technology have ensured that people are more likely to live with one or more chronic conditions. In Australia, the associated costs have led to a closer analysis of the way in which health care economists distribute funding in an increasingly market driven and commodified health care environment (Parker \& Aranda 1998). Chronic illnesses are incurable, permanent, often progressive in nature, and require long-term monitoring by health professionals (Lubkin 1998). People with chronic illnesses often experience personal economic pressures in addition to the health problems incurred by their illnesses (Covinsky et al. 1994).

As chronic illnesses are incurable, there is arguably no limit to the amount of funding that may be spent in attempting to improve the lives of people experiencing them, creating tension between their needs and health care funding. This tension has been evidenced in some Australian private 
hospitals that have been accused of turning away so called 'unprofitable' patients, the sick elderly and chronically ill, who have turned to an already over-loaded public system (Toy \& Foley 2001). It is inevitable that health care systems will become further burdened with the increasing prevalence of the chronically ill, making it imperative to address the specific issues related to the overall management of patients with comorbidities.

Nonfatal chronic conditions are associated with a disproportionate use of health services that are largely designed for episodic and acute care (Verbrugge \& Patrick 1995, Hoffman et al. 1996, Krop et al. 1998, Badley et al. 1999, 4Lubkin \& Larsen 2002). Increasing health care costs associated with hospital admission of people with comorbidities have been attributed primarily to prolonged length of stay, high readmission rates and the promotion of consumer satisfaction (Epstein et al. 1998). These are factors that have specific significance for the management of patients with comorbidities.

\section{Hospital length of stay and readmission rates}

Research has identified multiple reasons for the increased length of stay associated with chronic illnesses, including the presence of serious chronic respiratory diseases (Mushlin et al. 1991), the age of the patient (Breemhaar et al. 1990), noncompliance with prescribed therapies (Hay et al. 1997), complication rates (Whittington et al. 2000), and high comorbidity scores (Grau \& Kovner 1986). These factors are also associated with increased mortality and readmission rates (Jencks et al. 1988, Schaldach 1997, Librero et al. 1999, Ferrell et al. 2000).

Despite widespread efforts to standardize health care utilization in the USA, there are significant differences in length of stay for comparable illnesses, comorbidities and complication severity between institutions. This variability has been attributed in part to variations in medical practices (List et al. 1983, Jencks et al. 1988, Cleary et al. 1991), inadequate discharge supports (List et al. 1983), inadequate preadmission screening and early intervention benefits (Epstein et al. 1998) or inaccuracies in documenting comorbidities (Jencks et al. 1988) that can all clearly impact on quality of care.

The development and implementation of strategies to control hospital length of stay is a response to the high costs associated with the occupation of hospital beds (Hay et al. 1997). Reducing length of stay can impact on quality of care and the opportunity to oversee the management of the patient's comorbidities. Australia has seen the introduction of the Casemix patient classification system in 1988 (Picone \& Hathaway 1998) that was designed to create economic incentives to reduce length of stay (Hovenga 1998). Limitations of Casemix include its' inability to differentiate between primary and comorbid diseases in order to evaluate care (Greenfeld et al. 1993), and difficulty in estimating the exact nursing resource consumption per patient (Picone $\&$ Hathaway 1998).

Diagnosis-related group weights, which underpin Casemix funding are an index that represents the relative resource use for inpatient services (Picone \& Hathaway 1998). Little correlation has been found between the medically required length of stay and the expected length of stay based on diagnosis related groups, potentially placing quality of care at risk (Mushlin et al. 1991, Rutledge \& Osler 1998). In addition, diagnosis related groups and clinical pathways that provide health services within the shortest possible timeframe (Schaldach 1997, Hovenga 1998) have often under-estimated the actual length of stay required by patients with comorbidities (Munoz et al. 1988, Mushlin et al. 1991, Devo et al. 1992, Schaldach 1997). Indeed, shorter lengths of stay reduce the exposure of patients to medical personnel limiting medical staff's opportunity to co-ordinate and manage the treatment of the patients' comorbidities. As hospitals compete for business, the rapid throughput of patients increases the risk of not meeting all their needs (Cox 1996).

\section{Consumer satisfaction}

Consumer satisfaction plays a significant role in health care expenditure (Epstein et al. 1998), and is argued to be an important indicator of quality of care and outcomes (Cox 1996, Lin 1996, Ware et al. 1996, Armitage \& Kavanagh 1998, Epstein et al. 1998, Williams \& Ching 2000). As customers of care, it is imperative that patients receive quality care and are satisfied with this care (Huyke \& All 1999, Attree 2001, Gardner et al. 2001). The relationship between the patient and health care providers is an important determinant of patient satisfaction (Armitage \& Kavanagh 1998, Attree 2001).

The dynamics of the relationship between the nurse and patient with comorbidities, and the role of the nurse as patient advocate is especially important since the nurse has the most contact with the patient while in hospital. However, when using consumer reports of satisfaction with care it is important to acknowledge that specific client groups are more likely to report greater satisfaction with their care. This has been seen in patients with shorter hospital stays (Hay et al. 1997), people with less education and professional levels (Breemhaar et al. 1990), people receiving continuity of health care postdischarge (Ward 1990, Epstein et al. 1998), and the elderly (Breemhaar et al. 1990, Epstein et al. 1998, Higgs et al. 1998). In the case of the elderly, who often have 
comorbidities, caution must be applied when using patient satisfaction as an indicator of the efficacy of care. The elderly often play the role of the good, grateful, and docile patient

6(Breemhaar et al. 1990). Even if the measurement of efficacy of care incorporates issues about providing co-ordinated continuity of care of comorbidities, reliance on patient satisfaction is unlikely to reliably reflect the care provided (Ward 1990).

The current health care system in Australia does not facilitate the type of supportive care that people with chronic illnesses may require, such as care that assists them to cope, provides comfort, and facilitates the activities of daily living (Parker \& Aranda 1998). The lack of clear reimbursement guidelines for supportive care may contribute to doctors ignoring the presence of additional chronic conditions during consultation (Kaplan \& Feinstein 1974).

\section{The biomedical perspective}

The management of Australia's current health care system has been clearly influenced by the dominance of the biomedical approach of cure and research (Willis 1989). Most of the scientific research on comorbidity has addressed classification systems of comorbidities, the consequences of having comorbidities in the context of disability, psychological status, institutionalization, death, frequencies in populations and, to a lesser extent, theories about disease co-occurrence (Verbrugge et al. 1989). For example various comorbidity indexes have been developed to predict the risk of mortality (Feinstein 1970, Kaplan \& Feinstein 1974, Charlson et al. 1987, Iezzoni et al. 1992, D’Hoore et al. 1993, Poses et al. 1996), surgical complication rates (Concato et al. 1992, Greenfield et al. 1993, Brailer et al. 1996), functional status and well-being (Stewart et al. 1989, Lahad \& Yodfat 1993, Epstein et al. 1998), treatment evaluation (Parkerson et al. 1993, Katz et al. 1996), and resource utilization (Greenfield et al. 1988, Smith et al. 1997). However, these classification indexes bear little or no relationship to the nursing care and management of patients with comorbidities in the acute care setting, and between the hospital and community settings. Essentially there is limited research relating to the role of medicine in the treatment of patients' comorbidities in acute care. When a patient with chronic illnesses is admitted to an acute care setting, the focus of medical attention lies with curing the acute care problem.

The primary aim in the medical treatment of chronic diseases is to cure, or control symptoms (Brown \& Williams 1995, Lubkin 1998). Chronic diseases are characterized by their inability to be cured. This creates a paradox for the medical model, incurring frustrations, increasing the complexity of treatment and introducing limitations to treatment options. People with chronic diseases have been subjected to unnecessary diagnostic and therapeutic technology (Rutledge et al. 2001). The incurable nature of chronic diseases has also meant that medical treatment has had limited effectiveness in controlling symptoms and disease progression, particularly when considering some of the difficulties surrounding compliance and self-care (Baker \& Stern 1994, Thorne \& Paterson 1998, Paterson et al. 2001), a situation that is compounded in the presence of comorbidities (Redelmeier et al. 1998). The specialization of medicine has also meant that peoples' comorbidities are treated in isolation from one another. It is evident that a comprehensive approach to patients with chronic illnesses is needed to gain co-ordinated continuity of care (Ward 1990).

In addition, medical interventions have been evaluated on how they affect the course of the disease, rather than the person's overall functional ability and quality of life (Cluff 1981, Brown \& Williams 1995). For example, when multiple treatments are required for concurrent diseases, issues concerning medication adherence and the side-effects of such therapy can be more troublesome than the treatments themselves (Chubon et al. 1994, Wainwright \& Gould 1997, Butler et al. 1999). People with comorbidities have not always had access to treatment available to the general population, such as surgical interventions (Verbrugge et al. 1989, Devo et al. 1992), anticancer therapy (Greenfield et al. 1988, Lindsey et al. 1994), and medical treatment of comorbidities (Kaplan \& Feinstein 1974, Lindsey et al. 1994), while poorer prognoses has led to the argument that they have a lesser claim to intensive care resources (Swenson 1992). Under-treatment of patients' comorbidities may be more common when medications involve out-of-pocket expenses not covered by health care plans (Steinbrook 1998).

Indeed, the notion of comorbidity has at best been poorly or inconsistently defined in the medical literature (Charlson et al. 1987, Iezzoni et al. 1992, D’Hoore et al. 1993, Poses et al. 1996, Butler et al. 1999, Librero et al. 1999), although there is a general consensus that comorbidity means coexisting, multiple or concurrent diseases (Manton et al. 1991, Concato et al. 1992, Greenfield et al. 1993, Lindsey et al. 1994, McCormick et al. 1994, Kozma 1998). However, a wide range of diseases may be involved, making it difficult to compare findings and apply research to practice.

Clearly, there is confusion in differentiating between a comorbidity, secondary diagnosis and complication when defining comorbidity (Greenfield et al. 1988, Jencks et al. 1988, Iezzoni et al. 1992). Some authors state that the comorbidity has to be a medical problem (Munoz et al. 1988, Katz et al. 1996, Thomas 1997), not related to the primary 
diagnosis (Iezzoni et al. 1992), chronic (Manton et al. 1991, Iezzoni et al. 1992, Librero et al. 1999, Fillenbaum et al. 2000), or inclusive of acute diseases (Feinstein 1970, Greenfield et al. 1988, Thomas 1997), or a combination of acute and chronic diseases (Jones et al. 1999, Librero et al. 1999). Such 'nondisease' entities' as pregnancy (Feinstein 1970), or curable states of health such as tinea and dental problems (Liu et al. 1999), nosocomial infections and pressure sores (Greenfield et al. 1988) have been considered to be comorbidities, whilst cancer has been excluded (Romano et al. 1993). Brailer et al. (1996) attempted to differentiate carefully between the admitting diagnosis, secondary diagnosis, complication and comorbidity, but failed to clarify whether the comorbidities were strictly chronic in nature.

A further issue concerning the confusion over definition relates to the way in which the number of comorbidities per person has been counted in various studies. For example, comorbidities have been counted on admission (Greenfield et al. 1988, Munoz et al. 1988, Brailer et al. 1996), thus excluding in-house complications that other studies have included (Stewart et al. 1989, Cleary et al. 1991, Concato et al. 1992, Librero et al. 1999). Some studies have also relied on the patient self-report method of identifying comorbidities that may not always be accurate (Verbrugge et al. 1991, Lindsey et al. 1994, Kempen et al. 1997, Badley et al. 1999, Fillenbaum et al. 2000).

Whatever the case, chronic diseases have been, and are still, under-recorded (Romano et al. 1993, Kozma 1998, Librero et al. 1999, Humphries et al. 2000). The under-recording of comorbidities is due to several factors. First, most hospital records limit the number of diseases to be listed (Jencks et al. 1988, Iezzoni et al. 1992). Second, the sheer length of the International Classification of Diseases-9th revision, clinical modification, has made it impractical to use (Romano et al. 1993). Third, medical practitioners tend to record only those additional diagnoses that were the focus of treatment (Jencks et al. 1988, Romano et al. 1993) and fourth, acute diagnoses take precedence over chronic illnesses (Jencks et al. 1988). Failure to record comorbid diseases accurately in clinical notes has implications for acute care nurses who are guided by these in attempting to provide comprehensive nursing care.

It has been noted in the literature that both sociological and medical researchers tend to refer to specific diseases rather than use the term comorbidity (Verbrugge \& Patrick 1995, Kempen et al. 1997, Picavet \& van den Bos 1997, Badley et al. 1999, Butler et al. 1999). However, listing specific diseases can overlook the generalized problem of people with comorbidities. Further, medical research on comorbidities was not uncommon in the field of mental health, whereas combinations of medical and psychiatric diseases was unusual, unless as a result of the ageing process, such as dementia and heart failure (Laukkanen et al. 1997, Freedland \& Carney 2000, McGann 2000). Research studies often exclude patients with comorbidities to increase trial efficiency and generalisability of the findings (Feinstein 1970, Charlson et al. 1987, Stewart et al. 1989).

\section{The nurses' concern}

Sufferers of chronic illnesses are the people most likely to need nursing attention. This need will be more substantial as the number of disabling chronic illnesses increases (Verbrugge et al. 1989) and will contribute to a significant proportion of nursing work. However, the consumerist approach to health care in Australia has made such comprehensive nursing care difficult to provide (Parker 1999). Nursing has a professional responsibility to ensure that all patients receive comprehensive attention and care. This is reflected in the nursing profession's standards of professional conduct (Code of Professional Conduct for Nurses in Australia 1992), and moral and ethical grounding (Code of Ethics for Nurses in Australia 1993) that comple7 ments the International Council of Nurses' Code for Nurses (1973). Nurses support and enable individuals and their significant others to maintain, restore or improve their health status irrespective of the degree of disability, age or health status that is common to the experience of comorbidities.

Nurses are responsible for improving the health outcomes not only of the patient's acute illness but also simultaneously to provide co-ordinated care that will improve the health status related to their chronic conditions. However, anecdotal evidence suggests that this ongoing care and the opportunity to improve overall health outcomes in acute care is frequently overlooked. This situation is argued to be attributable to not only economic pressures but to the different underpinnings and perceived importance of acute and longterm care.

Inequities of the health care system have resulted from a failure to foresee the consequences of an ageing society (Toy $\&$ Foley 2001). Acute care has been favoured in an effort to cure diseases even though nonfatal chronic conditions far outweigh diseases considered potentially fatal (Verbrugge \& Patrick 1995, Lubkin \& Larson 2002). Medicine's overarching philosophy of cure upon which acute care is based is not currently appropriate for most patients because of their underlying chronic conditions (McElmurry et al. 1998). 
When a person with comorbidities is admitted to acute care, specialized medical knowledge is used to address the acute problem. Patients are then assumed to return to their previous autonomous life, free of disease. This is not the case with people with comorbidities. Additionally, high patient turn-over and the urgency of discharge places patients at risk of unmet needs (Cox 1996) that has particular significance for providing continuity of care, which frequently means long-term care (Evashwick 1996, Sparbel \& Anderson 2000). However, it has been claimed that health care professionals in the hospital and community frequently pass the coordination responsibilities for chronic illnesses back and forth leading to duplication and fragmentation of services, and increased health care costs (Papenhausen et al. 1998).

People with chronic illnesses often experience physical disability because diseases manifest in impaired physical functioning (Verbrugge et al. 1989). Caring for the chronically ill who are often also disabled, in acute care creates a conflict of interest between acute nursing and the on-going care that this group requires (Dewing 1991, Conway 1996).

\section{Discharge}

Once a person with comorbidities is discharged from hospital, little is known about their ongoing progress and outcomes (Jencks et al. 1988). Research has identified specific groups of people such as the elderly who have been discharged home quicker and sicker than previously in an attempt to contain health care costs (Proctor et al. 1996, Mistiaen et al. 1997, Bowman et al. 1998). On-going care postdischarge is predominantly met by women (Covinsky et al. 1994, Bowman et al. 1998) who ironically have more chronic illnesses and disability than men (Verbrugge et al. 1994). Additionally, effective discharge planning relates to the health of the whole person that includes health problems additional to the primary reason for admission (Armitage $\&$ Kavanagh 1998).

Various models of care have been developed in Australia to coordinate client care across care areas to arrange and connect health and social services to meet on-going health needs. Case management is one such model of service delivery (Hovenga 1998), and was developed as a means of assuring quality care, cost-effectiveness, and efficiency (Schaldach 1997). Yet, disease management programmes are based on specific diagnoses (Temmink et al. 2000) and risk neglecting additional comorbidities.

Specific gaps in care have been identified that impact negatively on the person's quality of life postdischarge, which include delayed entry of support systems and insufficient quality of help from formal and informal providers (Armitage \& Kavanagh 1998, Epstein et al. 1998). Nurses play a pivotal role in discharge planning which can reduce length of stay, reduce admission rates (Armitage \& Kavanagh 1998) and the amount of help required by the patient postdischarge 8(Epstein et al. 1998, Proctor et al. 1996).

At home people with chronic illnesses often require care, health professional visits, medications, medical equipment and house-keeping (Hoffman et al. 1996). The increasing responsibilities of the family in providing care in the face of limited external support raise major issues for nurses concerned with the welfare of others and equitable health care (Sarna \& McCorkle 1996, Parker 1999). Carers can become overwhelmed with increasingly complex treatment and care, and may sacrifice their own medical care in the process (Covinsky et al. 1994). This can result in caregiver burden that may lead to the patient having unmet needs or being institutionalized prematurely (Siegal et al. 1991, Mistiaen et al. 1997, Vrabec 1997).

There is little research to guide nurses in the complex management of patients with comorbidities in the acute setting. There is a need for greater understanding generally of the implications of having comorbidities and closer examination of perceptions of care in this context. As with medical research, there are very few studies that have examined the implications of suffering from a combination of psychiatric and somatic illnesses (Kaye et al. 2000), even though chronic illnesses are often accompanied by depression (Seeman et al. 1989).

\section{Discussion}

People with comorbidities have an underlying continuum of change and as the number of comorbidities increase, the person's general health scores relating to quality of life, which include well-being, mental status, self-rated health and mean activity levels, decline (Lahad \& Yodfat 1993, Verbrugge et al. 1994, Laukkanen et al. 1997). There is no doubt that the outcomes of experiencing multiple chronic illnesses necessitates nursing care, hospital stays, consultations with health practitioners in a variety of settings, and dependency on medication, equipment and people. People with comorbidities almost certainly will require acute care at some stage of their lives that will increase the complexity of care required. The acute care setting provides the opportunity for nurses to link resources and oversee the care and management of the patients' comorbidities to enable them to return home with an enhanced health status that can be maintained. Specifically, when a person with a variety of chronic conditions is admitted to acute care, the continuity and coordination of care requires careful consideration and research to guide nursing practice. 


\section{Conclusion}

Reduced mortality rates have resulted in a significant number of people living with chronic illnesses who have the potential to require repeated admissions to hospital for episodic care. This discussion has sought to explore the impact of the current health care environment in Australia that has made meeting the needs of these patients in the acute care setting and postdischarge difficult. People with comorbidities have additional needs as a result of their combined illnesses that increase the complexity of care required when admitted to hospital with an acute episode of illness. This has major implications for nurses caring for this group of people.

Currently patients with comorbidities are at risk of being neglected in acute care, predominantly because the current health care environment has not recognized adequately the special needs of these patients. The existing health care system in Australia and most western countries is straining to accommodate the increasingly chronic sick and elderly populations. The broad strategies implemented to contain health care costs are placing the care of people with comorbidities in danger of less than satisfactory care.

Dominant medical models of cure with an emphasis on specialization have particular implications for people suffering from comorbidities given that they fragment treatment by focusing on individual illnesses. Inconsistencies in defining and recording comorbidities make it difficult to understand fully the implications of comorbidities in the context of acute care delivery, much less to apply research findings to practice.

There is a clear need for research that informs health care professionals about the specific needs of people with comorbidities who experience an episodic illness event. More specifically, a greater understanding is needed of how episodic care can be integrated into the on-going care of people with comorbidities. Episodes of acute illness provide opportunities for nurses to acknowledge and review the overall management of patients with comorbidities whilst ensuring that changes in physical and psychosocial function as a consequence of acute illness are met.

\section{Implications for nursing practice and research}

A gap in the nursing knowledge about the experience of people with comorbidities in general and more specifically, in acute care has been identified. It is reasonable to question how patients with comorbidities are cared for, and how the care of their comorbidities is co-ordinated. Continuity of care is necessary in the management of chronic illnesses to reduce illness-related distress and to serve as a gate-keeping function for access to other services.

\section{References}

Armitage S. \& Kavanagh K. (1998) Consumer-oriented outcomes in discharge planning: a pilot study. Journal of Clinical Nursing 7, 67-74.

Attree M. (2001) Patients' and relatives' experiences and perspectives of 'Good' and 'Not so good' quality care. Journal of Advanced Nursing 33, 456-466.

Badley E., Howard M. \& Bombardier C. (1999) The relative impact of arthritis and other long term health problems in the population: a Canadian example. Working paper 99-2, March, The Toronto Hospital, Canada.

Baker C. \& Stern P. (1994) Finding meaning in chronic illness as the key to self care. Journal of Nursing Research 25, 23-36.

Bowman K., Rose J. \& Kresevic D. (1998) Family caregiving of hospitalised patients. Journal of Gerontological Nursing 24, 8-16.

Brailer D., Kroch E., Pauly M. \& Huang J. (1996) Comorbidityadjusted complication risk: a new outcome quality measure. Medical Care 34, 490-505.

Breemhaar B., Visser A. \& Kleunen J. (1990) Perceptions and behaviour among elderly hospital patients: description and explanation of age differences in satisfaction, knowledge, emotions and behaviour. Social Science and Medicine 31, 1377-1385.

Brown S. \& Williams A. (1995) Women's experiences of rheumatoid arthritis. Journal of Advanced Nursing 21, 695-701.

Butler R., August P., Ferdinand K., Phillips R. \& Roccella E. (1999) Hypertension: how comorbid disease influences choice of therapy. Geriatrics 54, 34-44.

Charlson M., Pompei P., Ales K. \& MacKenzie C. (1987) A new method of classifying prognostic comorbidity in longitudinal studies: development and validation. Journal of Chronic Diseases 40, 373-383.

Chubon S., Schulz R., Lingle E. \& Coster-Schulz M. (1994) Too many medications, too little money: how do patients cope? Public Health Nursing 11, 412-415.

Cleary P., Greenfield S., Mulley A., Pauker S., Schroeder S., Wexler L. \& McNeil B. (1991) Variations in length of stay and outcomes for six medical and surgical conditions in Massachusetts and California. Journal of the Amercian Medical Association 266, 73-79.

Cluff L. (1981) Chronic disease, function and the quality of care. Journal of Chronic Disease 34, 299-304.

Code of Ethics for Nurses in Australia. (1993). Australian Nursing Council Inc, Canberra, Australia.

Code of Professional Conduct for Nurses in Australia. (1992). Australian Nursing Council Inc, Canberra, Australia.

Concato J., Horwitz R., Feinstein A., Elmore J. \& Schiff S. (1992) Problems of comorbidity in mortality after prostatectomy. The Journal of the American Medical Association 267, 1077-1082.

Conway K. (1996) Nursing the physically disabled in a general hospital ward. Journal of Clinical Nursing 5, 121-125.

Covinsky K., Goldman L., Cook E., Oye R., Desbiens N., Reding D., Fulkerson W., Connors jr. A., Lynn J. \& Phillips R. (1994) The impact of serious illness on patients' families. The Journal of the American Medical Association 272, 1839-1844.

Cox C. (1996) Discharge planning for dementia patients: factors influencing caregiver decisions and satisfaction. Health and Social Work 21, 97-98. 
D’Hoore W., Sicotte C. \& Tilquin C. (1993) Risk adjustment in outcome assessment: the Charlson comorbidity index. Methods and Information in Medicine 32, 382-387.

Davis A. \& George J. (1998) States of Health: Health and Illness in Australia, 3rd edn. Addison-Wesley Longman, Melbourne, Australia.

Dawes M., Davies P., Gray A., Mant J., Seers K. \& Snowball R. (1999) Evidence-Based Practice. Churchill Livingstone, Edinburgh.

Devo R., Cherkin D. \& Ciol M. (1992) Adapting a clinical comorbidity index for use with ICD-9-CM administrative databases. Journal of Clinical Epidemiology 45, 613-619.

Dewing J. (1991) Physically disabled people in acute care. Nursing Standard 5, 37-39.

Epstein M., Turgeman A., Rotstein Z., Horoszowski H., Honig P., Baruch L. \& Noy S. (1998) Preadmission psychosocial screening of older orthopedic surgery patients: evaluation of a social work service. Social Work in Health Care 27, 1-25.

Evashwick C. (1996) The Continuum of Long-Term Care. Delmar, New York.

Feinstein A. (1970) The pre-therapeutic classification of comorbidity in chronic disease. Journal of Chronic Disease 23, 455-468.

Ferrell B., Josephson K., Norvid P. \& Alcorn H. (2000) Pressure ulcers among patients admitted to home care. Journal of the American Geriatrics Society 48, 1042-1047.

Fillenbaum G., Pieper C., Cohen H., Cornoni-Huntley J. \& Guralnik J. (2000) Comorbidity of five chronic health conditions in elderly community residents: determinants and impact on mortality. Journal of Gerontology: Medical Sciences 55A, M84-M89.

Freedland K. \& Carney R. (2000) Psychosocial considerations in elderly patients with heart failure. Clinics in Geriatric Medicine 16, 549-561.

Gardner A., Goodsell J., Duggan T., Murtha B., Peck C. \& Williams J. (2001) Don't call me sweetie!. Collegian 8, 32-38.

Gignac M. \& Cott C. (1998) A conceptual model of independence and dependence for adults with chronic physical illness and disability. Social Science and Medicine 47, 739-753.

Grau L. \& Kovner C. (1986) Comorbidity and length of stay: a case study. Nursing and Health Care 7, 426-430.

Greenfeld S., Apolone G., McNeil B. \& Cleary P. (1993) The importance of co-existent disease in the ocurrence of postoperative complications and one-year recovery in patients undergoing total hip replacement. Medical Care 31, 141-154.

Greenfield S., Aronow H., Elashoff R. \& Watanabe D. (1988) Flaws in mortality data: the hazards of ignoring comorbid disease. The Journal of the American Medical Association 260, 2253-2255.

Hamer S. \& Collinson G. (1999) Evidence-Based Practice. Bailliere Tindall, Edinburgh.

Hay J., Maldonado L., Weingarten S. \& Elldrodt A. (1997) Prospective evaluation of a clinical guideline recommending hospital length of stay in upper gastrointestinal tract haemorrage. The Journal of the American Medical Association 278, 2151-2157.

Higgs P., MacDonald L., MacDonald J. \& Ward M. (1998) Home from home: residents' opinions of nursing homes and long-stay wards. Age and Ageing 27, 199-205.

Hoffman C., Rice D. \& Sung H.-Y. (1996) Persons with chronic conditions: their prevalence and costs. The Journal of the American Medical Association 276, 1473-1479.
Hovenga E. (1998) Organisational performance evaluation. In: Management in the Australian Health Care Industry (Clinton M. \& Scheiwe D. eds), (2nd edn). Longman, South Melbourne, pp. 111-139.

Humphries K., Rankin J., Carere R., Buller C., Kiely F. \& Spinelli J. (2000) Comorbidity data in outcomes research: are clinical data derived from administrative data bases a reliable alternative to chart review? Journal of Clinical Epidemiology 53, 343-349.

Huyke L. \& All A. (1999) Quality in health care and ethical principles. Journal of Advanced Nursing 32, 562-571.

Iezzoni L., Foley S., Daley J., Hughes J., Fisher E. \& Heeren T. (1992) Comorbidities, complications and coding bias. The Journal of the American Medical Association 267, 2197-2203.

Jencks S., Williams D. \& Kay T. (1988) Assessing hospital-associated deaths from discharge data; the role of length of stay and comorbidities. The Journal of the American Medical Association 260, 2240-2246.

Jones K., Berrill W., Bromley C. \& Hendrick D. (1999) A confidential enquiry into certified asthma deaths in the North of England, 1994-96: influence of comorbidity and diagnostic accuracy. Respiratory Medicine 93, 923-927.

Kaplan M. \& Feinstein A. (1974) The importance of classifying initial comorbidity in evaluating the outcome of diabetes mellitus. Journal of Chronic Illness 27, 387-404.

Katz J., Chang L., Sangha O., Fossel A. \& Bates D. (1996) Can comorbidity be measured by questionnaire rather than medical record review? Medical Care 34, 73-84.

Kaye J., Morton J., Bowcutt M. \& Maupin D. (2000) Depression: the forgotten diagnosis among hospitalised adults. Journal of Neuroscience Nursing 32, 7-16.

Kempen G., Ormel J., Brilman E. \& Relyveld J. (1997) Adaptive responses among Dutch elderly: the impact of eight chronic medical conditions on health-related quality of life. American Journal of Public Health 87, 38-44.

Kozma C. (1998) Disease management: the role of comorbidities in disease state management. Managed Care Interface 11, 65-66.

Krop J., Haffer T., Powe N., Sauder C., Weller W. \& Anderson G. (1998) Patterns of expenditures and use of services among older adults with diabetes. Diabetes Care 21, 747-752.

Lahad A. \& Yodfat Y. (1993) Impact on comorbidity on well-being in hypertension: case control study. Journal of Human Hypertension 7, 611-614.

Laukkanen P., Sakari-Rantala R., Kauppinen M. \& Heikkinen E. (1997) Morbidity and disability in 75- and 80 year old men and women. A five year follow-up. Scandinavian Journal of Social Medicine 53 (Suppl.), 79-106.

LeMone P. \& Burke K. (2000) Medical Surgical Nursing: Critical Thinking in Client Care, 2nd edn. Addison-Wesley, California.

Librero J., Peiro S. \& Ordinana R. (1999) Chronic comorbidity and outcomes of hospital care, length of stay, mortality and readmission at 30 and 365 days. Journal of Clinical Epidemiology 52, 171-179.

Lin C. (1996) Patient satisfaction with nursing care as an outcome variable: dilemmas for nursing evaluation researches. Journal of Professional Nursing 12, 207-216.

Lindsey A., Larson P., Dodd M., Brecht M.-L. \& Packer A. (1994) Comorbidity, nutritional intake, social support, weight, and 
functional status over time in older cancer patients receiving radiotherapy. Cancer Nursing 17, 113-124.

List N., Fronczak N., Gottlieb S. \& Baker R. (1983) A cross-national study of differences in length of stay of patients with cardiac diagnoses. Medical Care 21, 519-530.

Liu M., Tsuji T., Tsujiuchi K. \& Chino N. (1999) Comorbidities in stroke patients as assessed with a newly developed comorbidity scale. American Journal of Physical Medicine and Rehabilitation 78, 416-424.

Lorig K., Sobel D., Stewart A., Brown B., Bandura A., Ritter P., Gonzales V., Laurent D. \& Holman H. (1999) Evidence suggesting that a chronic disease self-management program can improve health status while reducing hospitalization: a randomized trial. Medical Care 37, 5-14.

Lubkin I. (1998) Chronic Illness: Impact and Interventions, 4th edn. Jones \& Bartlett, Massachusetts.

Lubkin I. \& Larsen P. (2002) Chronic Illness: Impact and Interventions, 5th edn. Jones \& Bartlett, Massachusetts.

Manton K., Wrigley M., Cohen H. \& Woodbury M. (1991) Cancer mortality, aging, and patterns of comorbidity in the United States: 1968-86. Journal of Gerontology: Social Sciences 46, s225-s234.

McCormick W., Kukull W., van Belle G., Bowen J., Teri L. \& Larson E. (1994) Symptom patterns and comorbidity in the early stages of Alzheimer's disease. Journal of the American Geriatric Society 42, 517-521.

McElmurry B., Harris B., Misner S. \& Olson L. (1998) Nursing ethics in chronic illness. In: Chronic Illness: Impact and Interventions (Lubkin I. \& Larsen P. eds). Jones and Bartlett, Massachusetts, pp. 431-452.

McGann P. (2000) Comorbidity in heart failure in the elderly. Clinics in Geriatric Medicine 16, 631-648.

Miller J. (1992) Coping with Chronic Illness: Overcoming Powerlessness, 2nd edn. FA Davis, Philadelphia.

Mistiaen P., Duijnhouwer E., Wijkel D., de Bont M. \& Veeger A. (1997) The problems of elderly people at home one week after discharge from an acute care setting. Journal of Advanced Nursing 25, 1233-1240.

Munoz E., Friedman R., Gerold T., Sterman H., Goldstein J. \& Wise L. (1988) Financial risk, hospital cost, complications and comorbidities (CCs) in non-CC stratified urology diagnostic related groups. Urology 32(4), 380-384.

Mushlin A., Black E., Connolly C., Buonaccorso K. \& Eberly S. (1991) The necessary length of hospital stay for chronic pulmonary disease. The Journal of the American Medical Association 266, 80-83.

Ogle K., Swanson G., Woods N. \& Azzouz F. (2000) Cancer and comorbidity: redefining chronic diseases. American Cancer Society 88, 653-663.

Papenhausen J., Escandon-Dominguez S. \& Michaels C. (1998) Nursing case management. In: Chronic Illness: Impact and Interventions (Lubkin I. \& Larsen P. eds). Jones and Bartlett, Massachusetts, pp. 453-474.

Parker J. (1999) Patient or customer? Colleagian 6, 16-23.

Parker J. \& Aranda S. (1998) Palliative Care. MacLennan \& Petty, Sydney.

Parkerson G., Broadhead W. \& Tse C.-K. (1993) The Duke severity of illness checklist (DUSOI) for measurement of severity and comorbidity. Journal of Clinical Epidemiology 46, 379-393.
Paterson B., Russell C. \& Thorne S. (2001) Critical analysis of everyday self-care decision making in chronic illness. Journal of Advanced Nursing 35, 335-341.

Picavet H. \& van den Bos G. (1997) The contribution of six chronic conditions to the total burden of mobility disability in the Dutch population. American Journal of Public Health 87, 1680-1682.

Picone D. \& Hathaway V. (1998) Casemix; key issues for health care managers. In: Management in the Australian Health Care Industry, 2nd edn. (Clinton M. \& Scheiwe D. eds), Longman, South Melbourne, pp. 79-110.

Poses R., McClish D., Smith W., Bekes C. \& Scott W.E. (1996) Prediction of survival of critically ill patients by admission comorbidity. Journal of Clinical Epidemiology 49, 741-747.

Proctor E., Morrow-Howell N. \& Kaplan S. (1996) Implementation of discharge plans for chronically ill elders discharged home. Health and Social Work 21, 30-40.

Redelmeier D., Siew H., Tan M. \& Booth G. (1998) The treatment of unrelated disorders in patients with chronic medical diseases. New England Journal of Medicine 338, 1516-1520.

Romano P., Roos L. \& Jollis J. (1993) Further evidence concerning the use of a clinical comorbidity index with ICD-9-CM administrative data. Journal of Clinical Epidemiology 46, 1085-1090.

Rutledge D., Donaldson N. \& Pravikoff D. (2001) End-of-life care series. Part II. End-of-life care for hospitalized adults in America learnings from the SUPPORT and HELP studies. Online Journal of Clinical Innovations 4, 1-57.

Rutledge R. \& Osler T. (1998) The ICD-9 based illness severity score: a new model that outperforms both DRG and APR-DRG as predictors of survival and resource utilization. Journal of TraumaInjury Infection and Critical Care 45, 791-799.

Sarna L. \& McCorkle R. (1996) Burden of care and lung cancer. Cancer Practice: a Multidisciplinary Journal of Cancer Care 4, 245-251.

Schaldach D. (1997) Measuring quality and cost of care: evaluation of an amputation clinical pathway. Journal of Vascular Nursing XV, 13-20.

Seeman T.E., Guralnik J.M., Kaplan G.A., Knudsen L. \& Cohen R. (1989) The health consequences of multiple morbidity in the elderly: the Alameda county study. Journal of Aging and Health 1, $50-66$.

Siegal K., Raveis V., Houts P. \& Mor V. (1991) Caregiver burden and unmet patient needs. Cancer 68, 1131-1140.

Smeltzer S. \& Bare B. (2000) Brunner and Suddarth's Textbook of Medical-Surgical Nursing, 9th edn. Lippincott, Philadelphia.

Smith R., Hamalainen H., Kallio V., Ronnemaa T., Lind J., Puukka P., Arstila M. \& Kuttila K. (1997) Resource support and heart patient recovery. International Journal of Rehabilitation Research 20, 11-28.

Sparbel K. \& Anderson M. (2000) Integrated literature review of continuity of care: Part 1, conceptual issues. Journal of Nursing Scholarship 31, 17-24.

Steinbrook R. (1998) Patients with multiple chronic conditions- how many medications are enough? New England Journal of Medicine 338, 1541-1542.

Stewart A., Greenfield M., Hays R., Wells K., Rogers W., Berry McGlynn E. \& Ware J. Jr (1989) Functional status and well-being of patients with chronic conditions. The Journal of the American Medical Association 262, 907-913. 
Swenson M. (1992) Scarcity in the intensive care unit: principles of justice for rationing ICU beds. American Journal of Medicine 92, 551-555.

Temmink D., Francke A., Hutten J., van der Zee J. \& Abu-Saad H. (2000) Innovations in the nursing care of the chronically ill: a literature review from an international perspective. Journal of Advanced Nursing 31, 1449-1458.

Thomas C.L. ed. (1997) Taber's Cyclopaedic Medical Dictionary, 18th edn F A Davis, Philadelphia, Pennsylvania.

Thorne S. \& Paterson B. (1998) Shifting images of chronic illness. Image: Journal of Nursing Scholarship 30, 173-178.

Toy M.-A. \& Foley B. (2001) Health, a monster that eats millions. The Age newspaper, Melbourne, Australia, pp 1, 4.

Verbrugge L. \& Patrick D. (1995) Seven chronic conditions: their impact on US adults' activity levels and use of medical services. American Journal of Public Health 85, 173-182.

Verbrugge L., Lepkowski J. \& Imanaka Y. (1989) Comorbidity and its impact on disability. Milbank Quarterly 67, 450-484.

Verbrugge L., Lepkowski J. \& Konkol L. (1991) Levels of disability among US adults with arthritis. Journal of Gerontology 46, 571583.

Verbrugge L., Reoma J. \& Gruber-Baldini A. (1994) Short-term dynamics of disability and well-being. Journal of Health and Social Behaviour 35, 97-117.
Vrabec N. (1997) Literature review of social support and caregiver burden, 1980-95. Image Journal of Nursing Scholarship 29, 383388.

Wainwright S. \& Gould D. (1997) Non-adherence with medications in organ transplant patients: a literature review. Journal of Advanced Nursing 26, 968-977.

Ward R. (1990) Health care provider choice and satisfaction. In: The Legacy of Longevity: Health and Heath Care in Later Life (Stahl S. ed.). Sage, Newbury Park, California, pp. 273-290.

Ware J. Jr, Bayliss M., Rogers W., Kosinski M. \& Tarlov A. (1996) Differences in 4-year health outcomes for elderly and poor, chronically ill patients treated in HMO and fee-for-service systems: results from the Medical Outcomes Study. The Journal of the American Medical Asociation 276, 1039-1047.

Whittington K., Patrick M. \& Roberts J. (2000) A national study of pressure ulcer prevalence and incidence in acute care hospitals. Journal of WOCN 27, 209-215.

Williams A. \& Ching M. (2000) Day surgery: are patients satisfied? Nursing Review April 2000, 9.

Willis E. (1989) Medical Dominance. Unwin-Hyman, Sydney, Australia. 


\section{Author Query Form}

\section{Journal: $\quad$ JAN}

\section{Article: $\quad 2355$}

Dear Author,

During the copy-editing of your paper, the following queries arose. Please respond to these by marking up your proofs with the necessary changes/additions. Please write your answers on the query sheet if there is insufficient space on the page proofs. Please write clearly and follow the conventions shown on the attached corrections sheet. If returning the proof by fax do not write too close to the paper's edge. Please remember that illegible mark-ups may delay publication.

Many thanks for your assistance.

\begin{tabular}{|c|c|c|}
\hline $\begin{array}{l}\text { Query } \\
\text { reference }\end{array}$ & Query & Remarks \\
\hline 1 & Au: Please approve the suggested short title running head & \\
\hline 2 & Selim et al. 2001 has not been included in the list & \\
\hline 3 & Au: Please expand ASAP and AUST & \\
\hline 4 & $\begin{array}{l}\text { Lubkin \& Larson } 2002 \text { has been changed to Lubkin \& Larsen } 2002 \text { so } \\
\text { that this citation matches the list }\end{array}$ & \\
\hline 5 & $\begin{array}{l}\text { Greenfield et al. } 1993 \text { has been changed to Greenfeld et al. } 1993 \text { so } \\
\text { that this citation matches the list }\end{array}$ & \\
\hline 6 & $\begin{array}{l}\text { Breemhaar } 1990 \text { has been changed to Breemhaar et al. } 1990 \text { so that } \\
\text { this citation matches the list }\end{array}$ & \\
\hline 7 & $\begin{array}{l}\text { International Council of Nurses Code for Nurses } 1973 \text { has not been } \\
\text { included in the list }\end{array}$ & \\
\hline 8 & $\begin{array}{l}\text { Proctor et al. } 1998 \text { has been changed to Proctor et al. } 1996 \text { so that this } \\
\text { matches the list }\end{array}$ & \\
\hline
\end{tabular}




\section{Please correct and return this set}

Any errors in this proof which have been noticed by the printer's reader have been marked in green. If you see any more printer's errors, please mark them in red: there is no charge for correcting these mistakes. For your own alterations, please use black or blue or any colour other than green or red. Please use the proof correction marks shown below for all alterations and corrections.

\begin{tabular}{|c|c|c|}
\hline Instruction to printer & Textual mark & Marginal mark \\
\hline Leave unchanged & ... under matter to remain & Stet \\
\hline $\begin{array}{l}\text { Insert in text the matter } \\
\text { indicated in the margin }\end{array}$ & $h$ & $\begin{array}{l}\text { New matter followed by } \\
\boldsymbol{h}\end{array}$ \\
\hline Delete & $\mapsto$ through matter to be deleted & d] \\
\hline Delete and close up & E through matter to be deleted & मी \\
\hline $\begin{array}{l}\text { Substitute character or } \\
\text { substitute part of one or } \\
\text { more word(s) }\end{array}$ & $\begin{array}{l}\text { / through letter or } \mapsto \text { through } \\
\text { word }\end{array}$ & New letter or new word \\
\hline Change to italics & - under matter to be changed & س山 \\
\hline Change to capitals & $\equiv$ under matter to be changed & $\equiv$ \\
\hline Change to small capitals & $=$ under matter to be changed & $=$ \\
\hline Change to bold type & u under matter to be changed & $m$ \\
\hline Change to bold italic & $\bar{\approx}$ under matter to be changed & \\
\hline Change to lower case & Encircle matter to be changed & $\nRightarrow$ \\
\hline Change italic to upright type & (As above) & $\psi$ \\
\hline Insert 'superior' character & $\begin{array}{l}\text { / through character or } \wedge \text { where } \\
\text { required }\end{array}$ & $\begin{array}{l}y \text { under character } \\
\text { e.g. } y\end{array}$ \\
\hline Insert 'inferior' character & (As above) & $L$ over character e.g. $\frac{2}{2}$ \\
\hline Insert full stop & (As above & $\circ$ \\
\hline Insert comma & (As above) & , \\
\hline Insert single quotation marks & (As above) & $y$ and/or $y$ \\
\hline $\begin{array}{l}\text { Insert double quotation } \\
\text { marks }\end{array}$ & (As above) & 'y and/or $y$ \\
\hline Insert hyphen & (As above) & (4y) \\
\hline Start new paragraph & $r$ & $\sqrt{5}$ \\
\hline No new paragraph & 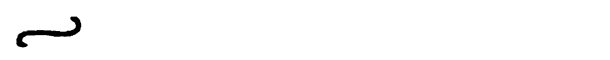 & 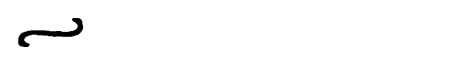 \\
\hline Transpose & $\sqrt{\sim}$ & $\sqrt{-1}$ \\
\hline Close up & linking $\approx$ letters & $=$ \\
\hline Insert space between letters & $\Lambda$ between letters affected & \# \\
\hline Insert space between words & $\boldsymbol{h}$ between words affected & \# \\
\hline Reduce space between letters & $\uparrow$ between letters affected & $T$ \\
\hline Reduce space between words & $\boldsymbol{\top}$ between words affected & \\
\hline
\end{tabular}




\section{University Library}

\section{- M M N E R VA A gateway to Melbourne's research publications}

Minerva Access is the Institutional Repository of The University of Melbourne

Author/s:

Williams, A;Botti, M

Title:

Issues concerning the on-going care of patients with comorbidities in acute care and postdischarge in Australia: a literature review

Date:

2002-10-01

Citation:

Williams, A. \& Botti, M. (2002). Issues concerning the on-going care of patients with comorbidities in acute care and post-discharge in Australia: a literature review. JOURNAL OF ADVANCED NURSING, 40 (2), pp.131-140. https://doi.org/10.1046/ j.1365-2648.2002.02355.x.

Publication Status:

Published

Persistent Link:

http://hdl.handle.net/11343/34489 